\title{
The role of adipokines in developmental programming: evidence from animal models
}

\author{
Clare M Reynolds and Mark H Vickers \\ Liggins Institute, University of Auckland, Auckland, New Zealand \\ Correspondence should be addressed to M H Vickers: m.vickers@auckland.ac.nz
}

This paper is part of a thematic section on 30 Years of the Developmental Endocrinology of Health and Disease. The guest editors for this section were Sean Limesand, Kent Thornburg and Jane Harding

\begin{abstract}
Alterations in the environment during critical periods of development, including altered maternal nutrition, can increase the risk for the development of a range of metabolic, cardiovascular and reproductive disorders in offspring in adult life. Following the original epidemiological observations of David Barker that linked perturbed fetal growth to adult disease, a wide range of experimental animal models have provided empirical support for the developmental programming hypothesis. Although the mechanisms remain poorly defined, adipose tissue has been highlighted as playing a key role in the development of many disorders that manifest in later life. In particular, adipokines, including leptin and adiponectin, primarily secreted by adipose tissue, have now been shown to be important mediators of processes underpinning several phenotypic features associated with developmental programming including obesity, insulin sensitivity and reproductive disorders. Moreover, manipulation of adipokines in early life has provided for potential strategies to ameliorate or reverse the adverse sequalae that are associated with aberrant programming and provided insight into some of the mechanisms involved in the development of chronic disease across the lifecourse.
\end{abstract}

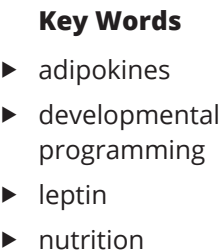

Journal of Endocrinology (2019) 242, T81-T94

\section{Introduction}

Data from epidemiological, clinical and experimental animal models has clearly demonstrated that the risk for developing abnormalities of metabolic and cardiovascular homeostasis and reproductive disorders in adult life is increased when developmental processes during early life have been adversely affected. In particular, changes in the nutritional environment during early life, including both undernutrition and overnutrition, can manifest as a range of cardiometabolic and reproductive disorders in offspring during adulthood. This relationship is preferentially termed 'developmental programming' or the 'Developmental Origins of Adult Health and Disease' (DOHaD).
Original observations by Professor David Barker highlighted the association between fetal growth restriction and later cardiometabolic disorders thus implying that alterations in the early life environment, including nutritional deprivation, provided a strong programming stimulus (Godfrey \& Barker 2000, Barker 2007). These early observations resulted in the development and characterisation of a wide range of experimental animal models, primarily in rodents, to induce fetal growth restriction. These studies have provided empirical evidence to support the programming hypothesis and highlight the link between early life adversity and later metabolic dysregulation in offspring. Although an initial 
focus was on fetal nutritional deprivation, given the rising prevalence of overweight/obesity, there has been increasing attention paid to the development of models utilising a maternal obesogenic environment and the consequences of early life nutritional excess on offspring outcomes (Elshenawy \& Simmons 2016, Godfrey et al. 2017). Of note, these disparate models often result in a commonality in programming effects in offspring with both maternal undernutrition and a maternal obesogenic environment resulting in increased obesity and cardiometabolic dysfunction in offspring. This may, in part, be attributed to obesogenic diets and 'overnutrition' representing a form of dietary malnutrition given that many obesogenic diets are commonly characterised by micronutrient deficiencies (Via 2012). The mechanisms that underpin nutritional programming in offspring following altered maternal nutritional environments are starting to be better defined but are overlaid by clear sexual dimorphism in responsiveness to different early life nutritional environments. It is also of note that different exposure windows to altered early life nutrition may elicit similar phenotypic outcomes in offspring but these can originate via different mechanistic pathways (Thompson et al. 2007, Howie et al. 2012, 2013).

The discovery of the adipose tissue-secreting adipokines (Zhang et al. 1994, Ahima et al. 2000) led to profound changes in the field of metabolic physiology. Following the characterisation of leptin in 1994, a large number of adipokines have now been characterised including adiponectin, apelin, visfatin and omentin. A wide range of experimental animal models have now clearly highlighted an important role for adipokines in developmental programming with adipokine dysregulation, in particular that of leptin, emerging as a common phenotypic feature in the pathogenesis of many programming-mediated metabolic, cardiovascular and reproductive disorders (Kieffer \& Habener 2000, Vickers et al. 2001, Horvath \& Bruning 2006).

The most widely studied adipokine to date in the setting of developmental programming is that of leptin. The product of the obesity $(o b)$ gene, leptin is a $16 \mathrm{kDa}$ hormone of 167 amino acids in length primarily secreted by adipose tissue (Zhang et al. 1994). The primary function of leptin is that of an afferent signal that acts via a negative feedback loop to maintain homeostatic control of adipose tissue mass. This then stimulates a negative energy balance controlling appetite and increasing energy expenditure (Friedman 2016). Leptin also exerts its actions across a wide number of areas including bone mass, cardiovascular health, the immune system and reproductive function. It is now clear from a range of experimental observations that maintenance of a 'critical' leptin level during early life development is required to facilitate the normal maturation of tissues and signalling pathways involved in metabolic homeostasis and reproductive function. As such, many aberrant adaptations which underlie developmental programming have been associated with a period of relative hypo- or hyperleptinemia during early developmental windows (Vickers \& Sloboda 2012a). Leptin was initially viewed as an anti-obesity hormone, preventing the storage of excess adipose tissue via a hypothalamic feedback loop acting to regulate food intake and increase energy expenditure (Hamann \& Matthaei 1996, Ahima \& Flier 2000). However, it has subsequently been demonstrated that most human obesity is associated with circulating hyperleptinemia, resulting from a state of leptin resistance (Considine et al. 1996). A number of animal models representing a range of species, strains and experimental paradigms have now provided clear evidence for a key role of leptin as a mediator of early life programming primarily via its actions as a central neurotropic factor and the potential impact of changes in the early life environment on the development of leptin circuitry related to energy balance and appetite control. Further, in addition to leptin, the impact of an altered early life environment on dysregulation of other, more recently characterised adipokines, is emerging across a range of animal studies including functional roles for these factors linking maternal adipose tissue and fetal growth via regulation of placental function.

\section{Rodents}

Rodent models have played a key role in our understanding of adipokines in the development of a range of programming-mediated disorders (Bouret 2010, Vickers \& Sloboda 2012a). In the setting of intrauterine growth restriction (IUGR), the predictive adaptive response (PARs) hypothesis suggests that the foetus makes physiological adaptations in order to optimise survival in a predicted environment of nutrient deprivation (Gluckman et al. 2005, Bateson et al. 2014). When a mismatch occurs between the anticipated and actual postnatal nutritional environment, the early adaptations become maladaptive and the risk for development of metabolic disorders is increased. The adipokines fit well within the PARs framework with clear evidence for altered adipokine 
profiles that arise as a consequence of perturbations in the early life environment that may confer adaptive benefits in the short term but later may be disadvantageous for example development of leptin resistance.

\section{Leptin}

Systemic leptin concentrations vary markedly during the fetal and early postnatal period, with a 5- to 10-fold increase in circulating leptin occurring in the first 2 weeks of neonatal life in female mice (Ahima et al. 1998). The mother's milk is an important source of leptin for postnatal rodents with greater access to milk-borne leptin to those suckled in small litters and thus exposed to early leptin-mediated neuroendocrine programming effects (reviewed in Spencer 2012).

A number of studies have reported relative hypoleptinemia in IUGR neonates arising due to a reduction in adipose mass at birth and/or decreased placental production (Desai et al. 2005, Briffa et al. 2017), but this later emerges as hyperleptinemia and increased adiposity in adulthood. Adult rat offspring subjected to severe maternal undernutrition (70\% food restriction) are hypoleptinemic at birth but develop obesity and hyperleptinemia as adults (Krechowec et al. 2006, Lecoutre et al. 2017a) with alterations in leptin and leptin receptor expression in white adipose tissue (Lecoutre et al. 2017a). These effects occur independently of the postnatal dietary environment but can be exacerbated by a postnatal high-fat diet (Vickers et al. 2000) with reduced locomotor activity and hyperphagia contributing to the increased fat mass (Vickers et al. 2000, 2005). Offspring of low protein (LP) fed mothers exhibit an increased appetite drive as evidenced by hyperphagia that is mediated by changes in circulating leptin and ghrelin levels and higher food conversion efficiency in parallel to lower adiponectin levels (Qasem et al. 2012). As with the PARs framework above, it was suggested that this collection of metabolic features in the LP offspring serves to maximise the potential for survival in a postnatal environment of nutritional scarcity and therefore represents a thrifty phenotype (Hales \& Barker 2001).

Studies in rodents have consistently reported that offspring of mothers fed an obesogenic diet prior to and throughout pregnancy and/or lactation are characterised by changes in energy balance and increased fat mass in adult life (Samuelsson et al. 2008, Kirk et al. 2009, Howie et al. 2013). The offspring phenotype is often associated with altered adipokine profiles in later life (Howie et al. 2009, Rajia et al. 2010). Rats that are overfed in the neonatal period following litter size reduction display early increases in circulating leptin that are maintained into adulthood and is associated with corresponding increases in body weight (Sominsky et al. 2017). These observations include hyperleptinemia and altered leptin gene expression coupled with disturbed central regulation of appetite control leading to hyperphagia (Rajia et al. 2010, Lecoutre et al. 2016). In addition, neonatal overfeeding using this paradigm results in a hypothalamic neuronal resistance to exogenous leptin in the neonatal period, although this leptin resistance is resolved by adulthood. Of note, short-term neonatal treatment with a leptin antagonist was not able to reverse the increased body weight or hyperleptinemia in the overfed offspring, suggesting factors other than leptin contributed to development of the phenotype. Such programming of leptin gene expression has been shown to be regulated via epigenetic modifications in an adipose tissue depot-specific manner (Lecoutre et al. $2017 b$ ). In this work, persistent epigenetic remodelling (both methylation and histone modifications) were shown to occur at regulatory regions within intergenic sequences and associated with changes in adipose-specific leptin gene expression in adult offspring of high-fat (HF)fed mothers.

In the setting of maternal obesity, leptin has been shown to play a role in the triggering of efferent sympathetic pathways to both thermogenic and nonthermogenic tissues (e.g. the kidney) and thus has been implicated in the developmental programming of hypertension (Taylor et al. 2014). Of note, in rodents a maternal obesogenic diet can result in growth restriction in offspring as a result of placental insufficiency (Mark et al. 2011). This is characterised by hypoleptinemia and hypoinsulinemia at birth but followed by rapid catch-up growth and hyperleptinemia and insulin resistance in adulthood (Howie et al. 2013). Offspring of HF-fed mothers also exhibit alterations in hypothalamic leptindependent STAT3 phosphorylation that are independent of the level of nutrition in the post-weaning period (Ferezou-Viala et al. 2007) with offspring from HF-fed mothers displaying reduced sensitivity to the anorectic effects of leptin (Walker et al. 2008).

In addition to HF diets, some attention has been given recently to the effects of diets high in sugar on maternal and offspring adipokine profiles. Fructose intake during pregnancy results in a diminished maternal leptin response to fasting and refeeding and is paralleled by fetal hyperleptinemia and an impairment in the transduction of the leptin signal in the foetus which may explain the 
hepatic steatosis observed in offspring in this model (Rodriguez et al. 2013).

In rodents, the early neonatal period is characterised by a surge in circulating leptin concentrations (Ahima et al. 1998) that is independent of fat accretion and body weight. Despite the increased systemic leptin concentrations, neonates are able to maintain a high level of food intake with both changes in feeding behaviour and responsiveness to leptin treatment being largely absent until near the time of weaning. These elevations in leptin concentrations in early life are proposed to play a role in brain development (Bouret \& Simerly 2007, Udagawa et al. 2007) whereby leptin acts as a potent neurotrophic factor that coordinates the establishment of the hypothalamic neuronal network responsible for the regulation of food intake (Bouret et al. 2004). A marked decrease in hypothalamic neuronal fibre density in leptin-deficient $o b / o b$ mice was observed in early work by Bouret and Simerly. This deficit could be normalised via leptin treatment in the neonatal period (Bouret et al. 2004), although the period of intervention was restricted to this early neonatal period of developmental plasticity with leptin treatment in the post-weaning period having no effect. Maternal undernutrition is well known to result in changes in the neonatal leptin surge. In the rodent, a maternal LP diet can delay the leptin surge (Bautista et al. 2008) and global food restriction can reduce the amplification of the surge (Delahaye et al. 2008). Furthermore, the IUGR-mediated delay and inhibition of the leptin surge can result in disorganisation of hypothalamic circuits leading to lasting effects on appetite control and energy balance including disordered development of pro-opiomelanocortin (POMC) neurons in the arcuate nucleus (Delahaye et al. 2008, Coupe et al. 2010). In the setting of maternal HF-feeding in the rat, alterations in the leptin surge have also been reported in offspring with a prolonged and amplified neonatal leptin surge accompanied by elevated leptin gene expression in visceral fat tissue (Kirk et al. 2009).

Given that leptin plays a key role in the control of puberty and fertility, there is also evidence from a range of rodent studies linking altered adipokine programming to later reproduction dysfunction in female offspring. These include early-onset puberty, premature ovarian ageing and alterations in reproductive fitness (Connor et al. 2012, Sominsky et al. 2016). In the rat, maternal undernutrition has been shown to significantly impact ovarian follicle number and increase markers of ovarian oxidative stress in adult offspring and thus can potentially contribute to the premature ovarian ageing seen in this model
(Bernal et al. 2010). Moreover, the effects of maternal undernutrition on the ovary were dependent upon the timing of the undernutrition with undernutrition during pregnancy and/or lactation eliciting differential programming effects. These changes appeared to occur in parallel to changes in leptin profiles. In particular, given that leptin is the permissive factor in the initiation of puberty, the early-onset puberty observed in these offspring may be a result of the increased adiposity and increased relative leptin concentrations observed in these animals following rapid catch-up growth in the early post-weaning period. Further, given that central leptin sensitivity and leptin receptor expression can be enhanced via estradiol (Clegg et al. 2006) and ovarianderived leptin is important for ovulation, steroidogenesis and oocyte maturation, changes in leptin receptor expression arising due to maternal undernutrition may contribute to the observed decrease in follicle number in offspring. Of note, when maternal undernutrition (50\% of ad libitum) encompasses the period of lactation (pregnancy and lactation or lactation alone), pubertal onset is delayed in pups of both sexes (Leonhardt et al. 2003). This may reflect a lack of catch-up growth in these animals during the pre-weaning period and further highlights the effects of different timing of developmental exposures on offspring outcomes (Howie et al. 2012). Similar to that observed in models of maternal undernutrition, neonatal overfeeding in the rat results in an acceleration in reproductive maturation and a decline in ovarian reserve with reduced ovulatory concentrations of gonadotropins, increases in circulating and ovarian leptin concentrations concomitant with increased leptin receptor expression in the ovary (Sominsky et al. 2016). A primary focus to date has been on programming of ovarian function in female offspring and there remains a paucity of data examining the altered timing of puberty in male offspring and examination of sex-specific responses to programming stimuli. Work by SánchezGarrido et al. highlighted important sexually dimorphic responses to various early nutritional challenges on the timing of pubertal onset (Sanchez-Garrido et al. 2013) and thus further work comparing both sexes is required to provide mechanistic insight into the role of adipokines in underpinning the different patterns of pubertal onset and related comorbidities observed between sexes.

In addition to models of altered maternal nutrition, alterations in adipokine profiles have also been investigated in models of glucocorticoid overexposure in utero. Dexamethasone to pregnant rats results in fetal growth retardation and hyperleptinemia and 
hyperinsulinemia in the mid-late gestation foetus (Ahmed 2016). However, adult rat offspring of mothers exposed to dexamethasone present with hyperglycemia and tissuespecific makers of insulin resistance but no changes in adipose leptin or resistin were observed across groups (Cleasby et al. 2003). Prenatal stress (restraint stress) in the rat has also been shown to result in basal hypoleptinemia and hyperglycemia in aged male offspring concomitant with fasting-induced hyperphagia (Lesage et al. 2004).

\section{Adiponectin}

Adiponectin modulates a number of metabolic processes, including fatty acid oxidation and glucose homeostasis with a reduced adiponectin expression commonly associated with impaired insulin sensitivity in animal models (Diez \& Iglesias 2003). Studies in rodents have provided evidence for adiponectin acting as a link between maternal adipose tissue and fetal growth via regulation of placental function (Aye et al. 2013). In adult male rat offspring of LP-fed mothers, adiponectin concentrations are reduced concomitant with insulin resistance, hyperphagia and increased visceral adiposity (Silvestre et al. 2014, De Oliveira et al. 2016). In the LP model used by Silvestre et al., adiponectin and adiponectin receptor expression was reduced in offspring adipose tissue, along with levels of peroxisome proliferatoractivated receptor (PPAR)- $\alpha$ and activity of AMP-activated protein kinase (AMPK) which are downstream targets of adiponectin. Thus, altered adiponectin signalling may lead to an impaired ability to inhibit adipogenesis and lipogenesis thus predisposing offspring to obesity and metabolic dysfunction in later life (Silvestre et al. 2014). Maternal obesity or gestational diabetes leads to reduced circulating levels of adiponectin and these mothers frequently deliver large babies with increased adiposity, who are susceptible to a range of perinatal complications and an increased risk for the development of metabolic syndrome in later life (Aye et al. 2015). In an obese mouse model of programming, circulating concentrations of both adiponectin and resistin were reduced in obese dams compared to lean counterparts and were associated with increased fetal weights, but the effects on offspring adipokine profiles were not examined (Kepczynska et al. 2013). Neonatal nutritional programming via alterations in litter size has been shown to impair adiponectin effects on energy homeostasis in adult male rats with animals raised in either small or large litters being unresponsive to the appetite-reducing effects of central adiponectin administration (Halah et al. 2018). Fructose intake through pregnancy alone induces hypoadiponectinemia concomitant with hyperinsulinemia and impaired insulin signalling in adult male, but not female, rat offspring independent of any changes in body weight (Rodriguez et al. 2016). In a mouse model of maternal fructose intake, female offspring exhibited reduced circulating adiponectin concentrations in parallel to hyperleptinemia, reduced insulin sensitivity and increased fat mass (Saad et al. 2016).

\section{Other adipokines}

In clinical studies, circulating concentrations of resistin, apelin and visfatin have been shown to be correlated with markers of bone formation in IUGR foetuses at term (Briana et al. 2014) but less is known about these adipokines experimentally. Resistin inhibits angiogenesis and induces insulin resistance. Data from clinical studies examining differences in resistin concentrations between IUGR and term groups suggest that resistin may not be directly involved in the regulation of adipogenesis and insulin sensitivity in the perinatal period with no differences in circulating concentrations observed between the groups (Briana et al. 2008).

First identified in 2004, visfatin (also known as preB-cell colony-enhancing factor (PBEF) or nicotinamide phosphoribosyltransferase (NAMPT)) has been suggested to act as an insulin mimetic and is highly enriched in visceral adipose tissue in both humans and rodents with circulating concentrations increasing in parallel with the development of obesity (Sonoli et al. 2011, Stastny et al. 2012). However, the associations of visfatin with obesity and diabetes has been a subject of controversy (Fukuhara et al. 2005, Arner 2006, Korner et al. 2007) and the evidence remains limited for its role in the setting of developmental programming. In a rat model of IUGR using uterine artery ligation, visfatin did not appear to be involved in the disturbed glucose metabolism in offspring and may only represent a marker of fat accumulation (Bouret 2010).

The adipokine apelin, discovered in 1998 (Tatemoto et al. 1998), is expressed and secreted by a range of tissues including adipose tissue, liver and brain, and its production is increased during adipocyte differentiation and is stimulated by insulin (Boucher et al. 2005). Apelin (and its receptor APJ) has been linked to a number of disease pathologies including obesity, diabetes and cardiovascular disease with recent work highlighting an important role in the regulation of glucose homeostasis. However, relatively little has been reported around the apelinergic system in the setting of developmental programming. 
Lecoutre et al. studied apelin regulation in adipose tissue in a model of severe maternal undenutrition and showed increased circulating apelin concentrations and adipose tissue apelin gene expression with a postnatal HF diet resulting in increased apelin receptor (APJ) and protein levels (Lecoutre et al. 2017a). Further work in this model revealed a role for apelin in the control of fetal and neonatal glucose homeostasis with maternal undernutrition drastically reducing apelinemia in both mothers and IUGR foetuses and altering expression of the apelinergic system at the fetal and placental interface (Mayeur et al. 2016). In the setting of maternal obesity in mice, the apelin system is altered at the fetal-maternal interface with placental apelin release and gene expression levels reduced by maternal obesity and maternal apelinemia increased at term in obese females. However, in contrast to the model of maternal undernutrition, no differences were observed in fetal plasma apelin concentrations between groups and longer term outcomes in offspring were not investigated (Hanssens et al. 2016).

Little has been reported around omentin, an adipokine with anti-inflammatory activity, in experimental models of developmental programming. Maternal circulating omentin profiles are similar between humans and rodents (Garces et al. 2015). In clinical studies, preexisting maternal obesity associates with a reduction in expression of omentin-1 in placenta, adipose tissue and maternal plasma and alterations in omentin- 1 in pregnancy were therefore proposed to play a role in the development of metabolic disorders in offspring in later life. However, experimental evidence remains limited (Barker et al. 2012).

\section{Large animal models (ovine, pig, NHP)}

There are some reported differences in the programming of adipokines and timing of critical windows between the rodent models and the large animal models. This is due, in part, to developmental events that occur in the early postnatal period in the rodent, particularly around hypothalamic development, occurring in utero in large animal models (Coupe et al. 2010, Mela et al. 2015, 2016). However, there is also evidence for some consistency, particularly as regards neonatal leptin, across both small and large animal models thus reflecting programming of effects on adipokines that are independent of the level of maturity at birth (Long et al. 2011).

\section{Leptin}

Maternal undernutrition throughout pregnancy in the sheep increases expression of the leptin receptor in the fetal hypothalamus in late gestation with levels largely normalised following improved maternal nutrition in the last trimester of pregnancy (Adam et al. 2015). In sheep, the impact of maternal undernutrition on circulating maternal leptin concentrations during late gestation has been shown to be dependent on fetal number with evidence that there is an increase in fetal adipose tissue in twins of ewes exposed to nutrient restriction throughout gestation (Edwards et al. 2005).

In the sheep, maternal obesity leads to a reduction in leptin signalling by the pituitary and altered regulation of the growth hormone (GH)/insulin-like growth factor (IGF)1 axis leading to appetite dysregulation, hyperleptinemia and increased adiposity in adult male offspring (Long etal. 2015, Tuersunjiang etal.2017). Despite developmental timing differences of central regulatory processes between rodents and large animal models, it has been shown that maternal obesity diminishes the plasma leptin peak in lamb neonates thus suggesting that similarities in neonatal leptin action exist in species born both immature and mature (Long et al. 2011). Moreover, it has also been shown that such changes in the leptin surge in sheep can be transmitted over generations with the impact of maternal overnutrition/obesity affecting the neonatal leptin surge in granddaughters (Shasa et al. 2015). Increased maternal nutrition results in increased leptin expression in adipose tissue in the postnatal lamb that are depot specific (Muhlhausler et al. 2007a). It has also been shown in the sheep that maternal obesity and an increased nutritional intake prior to and during pregnancy results in increased growth and adiposity in response to a feeding challenge and that this was paralleled by hyperphagia and hyperleptinemia (Long et al. 2010).

The role of adipokines and the development of brain circuits involved in the regulation of energy homeostasis in higher species remains limited (Grayson et al. 2010). In the non-human primate (NHP), a maternal HF diet can programme energy balance and hypothalamic signalling in offspring (Rivera et al. 2015, Sullivan et al. 2015, 2017) although adipokine profiles remain poorly characterised in these models. Further, although shown to be critical for brain development in rodents, there is limited evidence supporting a role for leptin in brain development in the NHP although leptin may play a role in the refinement of arcuate projection pathways (Grayson et al. 2010). https://joe.bioscientifica.com

https://doi.org/10.1530/JOE-18-0686 (c) 2019 Society for Endocrinology Published by Bioscientifica Ltd.
Printed in Great Britain 


\section{Adiponectin}

Recent work by Fensterseifer et al. reported in a sheep model that maternal obesity resulted in changes in adiponectin expression in fetal adipose tissue as well as adipogenic and circulating concentrations of total adiponectin. Although adiposity in pregnant ewes did not alter maternal adiponectin, it may have influenced fetal adipogenesis via alterations in the expression of adiponectin, PPAR- $\gamma$ and sterol regulatory element-binding factor (SREBF) 1 in fetal adipose tissue (Fensterseifer et al. 2018). Earlier work in the sheep had also reported that increased maternal nutrition (55\% above maintenance) led to stimulation of leptin and adiponectin mRNA expression in fetal perirenal adipose depots (Muhlhausler et al. 2007b).

As with the rodent models, the timing of the nutritional insult also impacts upon adipokine programming in the sheep. As an example, maternal overnutrition in the periconceptional period alone, although resulting in increased body fat mass in the postnatal lamb, has been shown to be independent of any changes in adipose tissue leptin or adiponectin expression (Rattanatray et al. 2010).

\section{Other adipokines}

Evidence is limited in large animal models for programming for other adipokines with a primary focus to date being around that of leptin and adiponectin action. The link between resistin and insulin resistance in the NHP model has been reported (Lu et al. 2015, Qi et al. 2015) but no data are available around its potential role in programmingmediated outcomes. Similarly, there is limited evidence for a role of apelin in the sheep via its involvement in the development of central feeding processes (Sato et al. 2012), but this has not been investigated in the setting of development programming.

\section{Intervention strategies}

A number of studies in experimental animal models have now shown that some disorders induced as a consequence of aberrant developmental programming are potentially reversible by modulation of adipokines during early life windows of developmental plasticity (Vickers \& Sloboda $2012 a, b)$. In particular, manipulation of the leptin axis has shown to reverse many of the postnatal sequalae in offspring arising due to programming effects (Vickers \& Sloboda 2012a,b). Neonatal leptin treatment to rat offspring born following maternal undernutrition can ameliorate many of the effects associated with maternal deprivation including normalisation of body weight, fat mass, circulating leptin concentrations, bone parameters and locomotor activity (Vickers et al. 2005, Gluckman et al. 2007a, Firth et al. 2017). Of note, these effects appear to be sexually dimorphic in nature with increased benefits of leptin treatment seen in programmed female offspring compared to males. Moreover, whereas leptin treatment to male offspring of undernourished mothers conferred protection against programming-induced disorders, treatment of offspring from control pregnancies led to an increase in diet-induced body weight gain and related adverse metabolic sequelae, including hyperinsulinemia and increased total body adiposity (Vickers et al. 2008). This may be the result of leptin treatment to control animals creating an amplified and prolonged leptin surge as has been shown in offspring of obese mothers with similar effects observed on offspring outcomes (Kirk et al. 2009). This suggests that the effect of leptin treatment in the neonatal period on later offspring outcomes is dependent upon both maternal nutritional status and the sex of the offspring. This was highlighted in further work in this model whereby the effects of neonatal leptin treatment on hepatic gene expression and epigenetic status in adulthood were directionally dependent on the animal's nutritional status in utero (Gluckman et al. 2007b).

In the maternal LP rat model, leptin administration normalised the reduction in fetal IGF-1 concentrations and significantly increased fetal IGF-2 and leptin concentrations (Stocker et al. 2004). These effects positively impacted upon the development of key organs including the fetal pancreas and thus conferred longterm protection against the development of obesity and type 2 diabetes (Stocker et al. 2007). A limitation of this study was that leptin administration was not undertaken in the normal pregnancy group; as previous work has suggested that leptin treatment in the setting of normal pregnancies could elicit an adverse offspring outcome (Vickers et al. 2008). In the piglet, early postnatal leptin treatment following IUGR promoted organ maturation and development with notable changes in weight and structure across a range of tissues including liver, spleen, pancreas, kidney and ovaries (Attig et al. 2008a).

The model of neonatal leptin treatment has provided some empirical evidence to support the PARs hypothesis as developmental outcome was altered by experimentally manipulating the predicted environment that is using leptin to signal a high nutrient postnatal environment. Conversely, it has also been shown that blocking leptin 
action in the early postnatal period (via treatment with a leptin antagonist) results in programming of leptin resistance and increased susceptibility to diet-induced obesity in rodents (Attig et al. 2008b). Further work by Mela et al. showed that treatment in the rat with a leptin antagonist from PND 5 to 9, coincident with peak leptin levels in the neonatal surge, resulted in changes in reproductive factors in the hypothalamus which impact upon sexual maturation including modifying the timing of pubertal onset and leading to persisting changes on hypothalamic expression on reproductive neuropeptides (Mela et al. 2015, 2016).

It must be noted that in addition to dose and timing of administration, some of the observed differences in outcomes of leptin treatment studies may also reflect the type of leptin used. Human leptin has been shown to have diuretic/natriuretic activity in the rodent and thus consideration needs to be made when examining programming-mediated effects around blood pressure regulation and renal function (Jackson \& Li 1997).

In the setting of IUGR in male rat offspring (via uterine artery ligation), increased visceral adiposity was accompanied by a dysregulation in the expression of peroxisome proliferator activated receptor (PPAR)- $\gamma$ expression. Given that activation of PPAR- $\gamma$ can increase adiponectin expression in subcutaneous adipose tissue and normalise visceral adipose deposition, it was proposed that maternal supplementation with a PPAR agonist could normalise adipose regulation in IUGR offspring (Bagley et al. 2013). Indeed, supplementation to the maternal diet with docosahexaenoic acid (DHA), a known PPAR- $\gamma$ agonist, has been shown to normalise IUGR-mediated changes in adipose tissue deposition, increased circulating adiponectin concentrations and reversed programminginduced changes in adipose tissue adiponectin and adiponectin receptor expression in male rats (Bagley et al. 2013). However, as with leptin, these effects appear to be sex specific with IUGR and DHA-induced changes in adipose tissue depots and altered PPAR regulation observed in male but not female offspring (Joss-Moore et al. 2010, Bagley et al. 2013)

Treatment of pregnant mice with adiponectin can prevent the adverse consequences of maternal obesity on placental function and fetal growth (Aye et al. 2015). In obese mouse dams, placental insulin and mammalian target of rapamycin complex 1 (mTORC1) signalling was activated, placental transport of glucose and amino acids was increased, PPAR $\alpha$ phosphorylation was reduced and there was an increase in fetal weights of approximately $30 \%$. Maternal adiponectin infusion in these obese mice led to a normalisation of maternal insulin sensitivity, nutrient transport, placental insulin/mTORC1 and PPAR $\alpha$ signalling and fetal growth independent of the effects on maternal fat mass (Aye et al. 2015). Further work by Paulsen et al. has also shown that normalisation of adiponectin levels of maternal obesity in the mouse prevented the development of adverse metabolic outcomes in male offspring (Paulsen et al. 2018) and thus suggests that low circulating maternal adiponectin may represent a critical mechanistic link between a maternal obesogenic environment and the development of metabolic disease in offspring.

\section{Discussion}

Alterations in adipokine profiles, particularly leptin, have been examined across a wide range of experimental animal models of developmental programming. It is now clear that maternal undernutrition and obesity during pregnancy and/or lactation all produce offspring characterised by obesity and leptin resistance, the effects of which can be exacerbated as a result of rapid postnatal catch-up growth and exposure to a post-weaning obesogenic dietary environment (Fig. 1). A primary focus to date on the role of adipokines has been on alterations in the early life nutritional environment with undernutrition and overnutrition both resulting in marked alterations in adipokine profiles, the timing and magnitude of the leptin surge and wiring of the hypothalamic circuits regulating appetite control and energy expenditure. There is also evidence that leptin can act as a metabolic signal to the reproductive system via direct actions at the ovarian level (Spicer \& Francisco 1997, Bernal et al. 2010) leading to outcomes including early onset puberty and markers of early ovarian ageing.

Leptin has been the most widely studied adipokine to date. Although leptin is expressed in the placenta and in certain fetal tissues, the role of leptin as a regulator of fetal growth still remains unclear (Hoggard et al. 2001, Hauguel-De Mouzon et al. 2006). It also needs to be noted that models of maternal diabetes need to be differentiated from those models of maternal obesity per se. Circulating leptin concentrations can be reduced in offspring of obese pregnancies whereas offspring of diabetic mothers are often characterised by macrosomia and hyperleptinemia.

Although the leptin surge has been characterised across a range of small animal models, it is not as well defined in larger animal models such as the sheep or NHP. Most hypothalamic development in rodents occurs in 


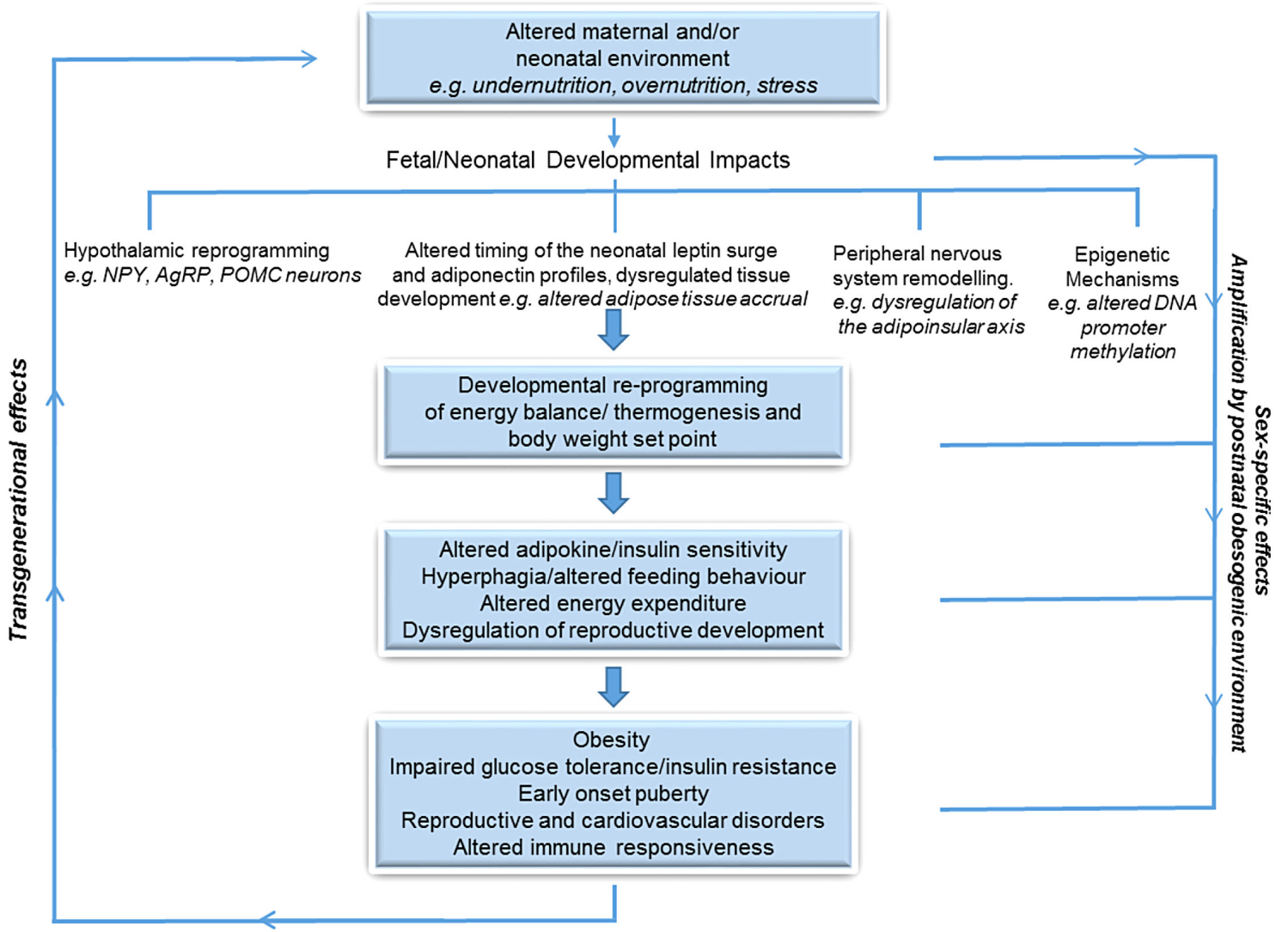

\section{Figure 1}

The impact of an altered early life environment on developmental programming of energy balance, adipokine regulation and consequences for later life metabolic, reproductive and cardiovascular health in offspring.

the early postnatal period thus aligns with the timing of the neonatal surge whereas these processes largely occur in utero in large animal models (Grove et al. 2005). It is important to note therefore that a leptin surge in utero may not arise from the mother, as leptin does not cross the placenta. In larger animal models and that of the human, it is more likely that insulin, which can cross the placenta and enter the fetal brain, interacts with leptin signalling via the adipoinsular axis feedback loop (Vickers et al. 2001, Horvath \& Bruning 2006). Indeed, offspring born to women with obesity or type 2 diabetes have an increased risk of developing metabolic disorders (Grove et al. 2005) although whether this is the result of developmental alterations in hypothalamic circuits remains to be addressed. However, despite these differences in timing of developmental events across model species, there are reports of a neonatal leptin surge in the sheep which can be modified by maternal nutritional status thus providing some commonality across small and large animal models.

Although leptin has received the most attention, there is evidence across a wide range of models for dysregulation of other key adipokines, particularly that of adiponectin. It is also notable that despite the variety of experimental paradigms used to disrupt the early life nutritional environment (global calorie restriction, LP, HF and high sugar diets), similar effects on adipokine dysregulation in adult life have been reported, suggesting common mechanistic pathways may underpin the programming of later disease in later life. These manipulations appear to increase susceptibility to obesity in offspring via dysregulating the normal development of central neural pathways involved in the regulation of appetite, energy expenditure and storage with central and peripheral leptin resistance a common phenotypic outcome. It is likely that leptin, given its strong neurotropic properties, is a major mediator of these early developmental changes. Experimental data also suggest that this activity is restricted to the early life period that precedes leptin's acute regulation of food intake in adults (Myers et al. 2008) with intervention strategies using leptin showing efficacy in the early neonatal period but largely ineffectual when used in the post-weaning period when leptin resistance is present. 
Taken together, the evidence to date clearly highlights the important of the adipokines in programmingrelated disorders with manipulation of these factors offering key insight into mechanisms underpinning the development of obesity and disorders of energy balance and also avenues for potential interventions to reverse the programming process. However, it is important to note that neurodevelopmental events that occur in rodents in the neonatal period occur in utero in primates, including humans (Grove et al. 2005, Horvath \& Bruning 2006, Sullivan et al. 2011). In rodents, maternally derived leptin can impact on the development of the regulatory neural networks that affect appetite control and on the subsequent regulation of leptin synthesis and the risk for obesity and related metabolic disorders in the offspring. However, in larger model species such as the NHP and sheep, there is also evidence that the synthesis and secretion of adipokines are regulated in fetal life (Mcmillen et al. 2006). More work needs to be undertaken around the potential epigenetic processes involved and the impact of alterations in the early periods of developmental plasticity on epigenetic regulation of adipokines. As an example, programming-mediated changes in methylation of the suppressor of cytokine signalling (SOCS)-3 may have persisting effects on the leptin-insulin feedback loop (the adipoinsular axis; Vickers et al. 2001) via inhibition of leptin signal transduction (Holness \& Sugden 2006). As such, the use of epigenomic approaches and identification of target sites (e.g. methylation sites, miRNAs) involved in the epigenetic regulation of adipokine action is an increasingly important area of investigation.

\section{Declaration of interest}

The authors declare that there is no conflict of interest that could be perceived as prejudicing the impartiality of this review.

\section{Funding}

This work did not receive any specific grant from any funding agency in the public, commercial or non-for-profit sector.

\section{References}

Adam CL, Williams PA, Milne JS, Aitken RP \& Wallace JM 2015 Orexigenic gene expression in late gestation ovine foetal hypothalamus is sensitive to maternal undernutrition and realimentation. Journal of Neuroendocrinology 27 765-771. (https://doi. org/10.1111/jne.12302)

Ahima RS \& Flier JS 2000 Leptin. Annual Review of Physiology 62 413-437. (https://doi.org/10.1146/annurev.physiol.62.1.413)
Ahima RS, Prabakaran D \& Flier JS 1998 Postnatal leptin surge and regulation of circadian rhythm of leptin by feeding. Implications for energy homeostasis and neuroendocrine function. Journal of Clinical Investigation 101 1020-1027. (https://doi.org/10.1172/JCI1176)

Ahima RS, Saper CB, Flier JS \& Elmquist JK 2000 Leptin regulation of neuroendocrine systems. Frontiers in Neuroendocrinology 21 263-307. (https://doi.org/10.1006/frne.2000.0197)

Ahmed RG 2016 Gestational dexamethasone alters fetal neuroendocrine axis. Toxicology Letters 258 46-54. (https://doi.org/10.1016/j. toxlet.2016.05.020)

Arner P 2006 Visfatin - a true or false trail to type 2 diabetes mellitus. Journal of Clinical Endocrinology and Metabolism 91 28-30. (https://doi. org/10.1210/jc.2005-2391)

Attig L, Djiane J, Gertler A, Rampin O, Larcher T, Boukthir S, Anton PM, Madec JY, Gourdou I \& Abdennebi-Najar L 2008a Study of hypothalamic leptin receptor expression in low-birth-weight piglets and effects of leptin supplementation on neonatal growth and development. American Journal of Physiology: Endocrinology and Metabolism 295 E1117-E1125. (https://doi.org/10.1152/ ajpendo.90542.2008)

Attig L, Solomon G, Ferezou J, Abdennebi-Najar L, Taouis M, Gertler A \& Djiane J 2008b Early postnatal leptin blockage leads to a longterm leptin resistance and susceptibility to diet-induced obesity in rats. International Journal of Obesity 32 1153-1160. (https://doi. org/10.1038/ijo.2008.39)

Aye IL, Powell TL \& Jansson T 2013 Adiponectin - the missing link between maternal adiposity, placental transport and fetal growth? Placenta 34 (Supplement) S40-S45. (https://doi.org/10.1016/j. placenta.2012.11.024)

Aye IL, Rosario FJ, Powell TL \& Jansson T 2015 Adiponectin supplementation in pregnant mice prevents the adverse effects of maternal obesity on placental function and fetal growth. PNAS 112 12858-12863. (https://doi.org/10.1073/pnas.1515484112)

Bagley HN, Wang Y, Campbell MS, Yu X, Lane RH \& Joss-Moore LA 2013 Maternal docosahexaenoic acid increases adiponectin and normalizes IUGR-induced changes in rat adipose deposition. Journal of Obesity 2013 312153. (https://doi.org/10.1155/2013/312153)

Barker DJ 2007 The origins of the developmental origins theory. Journal of Internal Medicine 261 412-417. (https://doi.org/10.1111/j.13652796.2007.01809.x)

Barker G, Lim R, Georgiou HM \& Lappas M 2012 Omentin-1 is decreased in maternal plasma, placenta and adipose tissue of women with preexisting obesity. PLoS ONE 7 e42943. (https://doi.org/10.1371/journal. pone.0042943)

Bateson P, Gluckman P \& Hanson M 2014 The biology of developmental plasticity and the predictive adaptive response hypothesis. Journal of Physiology 592 2357-2368. (https://doi.org/10.1113/ jphysiol.2014.271460)

Bautista CJ, Boeck L, Larrea F, Nathanielsz PW \& Zambrano E 2008 Effects of a maternal low protein isocaloric diet on milk leptin and progeny serum leptin concentration and appetitive behavior in the first 21 days of neonatal life in the rat. Pediatric Research 63 358-363. (https:// doi.org/10.1203/01.pdr.0000304938.78998.21)

Bernal AB, Vickers MH, Hampton MB, Poynton RA \& Sloboda DM 2010 Maternal undernutrition significantly impacts ovarian follicle number and increases ovarian oxidative stress in adult rat offspring. PLOS ONE 5 e15558. (https://doi.org/10.1371/journal.pone.0015558)

Boucher J, Masri B, Daviaud D, Gesta S, Guigne C, Mazzucotelli A, Castan-Laurell I, Tack I, Knibiehler B, Carpene C, et al. 2005 Apelin, a newly identified adipokine up-regulated by insulin and obesity. Endocrinology 146 1764-1771. (https://doi.org/10.1210/en.20041427)

Bouret SG 2010 Leptin, nutrition, and the programming of hypothalamic feeding circuits. Nestle Nutrition Workshop Series: Paediatric Programme 65 25-35; discussion 35-39. (https://doi. org/10.1159/000281143) https://joe.bioscientifica.com https://doi.org/10.1530/JOE-18-0686
(C) 2019 Society for Endocrinology Published by Bioscientifica Ltd.
Printed in Great Britain 
Bouret SG \& Simerly RB 2007 Development of leptin-sensitive circuits. Journal of Neuroendocrinology 19 575-582. (https://doi.org/10.1111/ j.1365-2826.2007.01563.x)

Bouret SG, Draper SJ \& Simerly RB 2004 Trophic action of leptin on hypothalamic neurons that regulate feeding. Science 304 108-110. (https://doi.org/10.1126/science.1095004)

Briana DD, Boutsikou M, Baka S, Gourgiotis D, Marmarinos A, Hassiakos D \& Malamitsi-Puchner A 2008 Perinatal changes of plasma resistin concentrations in pregnancies with normal and restricted fetal growth. Neonatology 93 153-157. (https://doi.org/10.1159/000108412)

Briana DD, Boutsikou M, Boutsikou T \& Malamitsi-Puchner A 2014 Associations of novel adipocytokines with bone biomarkers in intra uterine growth-restricted fetuses/neonates at term. Journal of MaternalFetal and Neonatal Medicine 27 984-988. (https://doi.org/10.3109/147 67058.2013.852533)

Briffa JF, O'dowd R, Moritz KM, Romano T, Jedwab LR, Mcainch AJ, Hryciw DH \& Wlodek ME 2017 Uteroplacental insufficiency reduces rat plasma leptin concentrations and alters placental leptin transporters: ameliorated with enhanced milk intake and nutrition. Journal of Physiology 595 3389-3407. (https://doi.org/10.1113/JP273825)

Cleasby ME, Kelly PA, Walker BR \& Seckl JR 2003 Programming of rat muscle and fat metabolism by in utero overexposure to glucocorticoids. Endocrinology 144 999-1007. (https://doi. org/10.1210/en.2002-220559)

Clegg DJ, Brown LM, Woods SC \& Benoit SC 2006 Gonadal hormones determine sensitivity to central leptin and insulin. Diabetes $\mathbf{5 5}$ 978-987. (https://doi.org/10.2337/diabetes.55.04.06.db05-1339)

Connor KL, Vickers MH, Beltrand J, Meaney MJ \& Sloboda DM 2012 Nature, nurture or nutrition? Impact of maternal nutrition on maternal care, offspring development and reproductive function. Journal of Physiology 590 2167-2180. (https://doi.org/10.1113/ jphysiol.2011.223305)

Considine RV, Sinha MK, Heiman ML, Kriauciunas A, Stephens TW, Nyce MR, Ohannesian JP, Marco CC, Mckee LJ \& Bauer TL 1996 Serum immunoreactive-leptin concentrations in normal-weight and obese humans. New England Journal of Medicine 334 292-295. (https:// doi.org/10.1056/NEJM199602013340503)

Coupe B, Amarger V, Grit I, Benani A \& Parnet P 2010 Nutritional programming affects hypothalamic organization and early response to leptin. Endocrinology 151 702-713. (https://doi.org/10.1210/ en.2009-0893)

De Oliveira JC, Gomes RM, Miranda RA, Barella LF, Malta A, Martins IP, Franco CC, Pavanello A, Torrezan R, Natali MR, et al. 2016 Protein restriction during the last third of pregnancy malprograms the neuroendocrine axes to induce metabolic syndrome in adult male rat offspring. Endocrinology 157 1799-1812. (https://doi.org/10.1210/ en.2015-1883)

Delahaye F, Breton C, Risold PY, Enache M, Dutriez-Casteloot I, Laborie C, Lesage J \& Vieau D 2008 Maternal perinatal undernutrition drastically reduces postnatal leptin surge and affects the development of arcuate nucleus POMC neurons in neonatal male rat pups. Endocrinology 1496.

Desai M, Gayle D, Babu J \& Ross MG 2005 Programmed obesity in intrauterine growth-restricted newborns: modulation by newborn nutrition. American Journal of Physiology: Regulatory, Integrative and Comparative Physiology 288 R91-R96. (https://doi.org/10.1152/ ajpregu.00340.2004)

Diez JJ \& Iglesias P 2003 The role of the novel adipocyte-derived hormone adiponectin in human disease. European Journal of Endocrinology 148 293-300. (https://doi.org/10.1530/eje.0.1480293)

Edwards LJ, Mcfarlane JR, Kauter KG \& Mcmillen IC 2005 Impact of periconceptional nutrition on maternal and fetal leptin and fetal adiposity in singleton and twin pregnancies. American Journal of Physiology: Regulatory, Integrative and Comparative Physiology 288 R39-R45. (https://doi.org/10.1152/ajpregu.00127.2004)
Elshenawy S \& Simmons R 2016 Maternal obesity and prenatal programming. Molecular and Cellular Endocrinology 435 2-6. (https:// doi.org/10.1016/j.mce.2016.07.002)

Fensterseifer SR, Austin KJ, Ford SP \& Alexander BM 2018 Effects of maternal obesity on maternal and fetal plasma concentrations of adiponectin and expression of adiponectin and its receptor genes in cotyledonary and adipose tissues at mid- and late-gestation in sheep. Animal Reproduction Science 197 231-239. (https://doi.org/10.1016/j. anireprosci.2018.08.033)

Ferezou-Viala J, Roy AF, Serougne C, Gripois D, Parquet M, Bailleux V, Gertler A, Delplanque B, Djiane J, Riottot M, et al. 2007 Long-term consequences of maternal high-fat feeding on hypothalamic leptin sensitivity and diet-induced obesity in the offspring. American Journal of Physiology: Regulatory, Integrative and Comparative Physiology 293 R1056-R1062. (https://doi.org/10.1152/ajpregu.00117.2007)

Firth EC, Gamble GD, Cornish J \& Vickers MH 2017 Neonatal leptin treatment reverses the bone-suppressive effects of maternal undernutrition in adult rat offspring. Scientific Reports $\mathbf{7} 7686$ (https://doi.org/10.1038/s41598-017-07500-5)

Friedman J 2016 The long road to leptin. Journal of Clinical Investigation 126 4727-4734. (https://doi.org/10.1172/JC191578)

Fukuhara A, Matsuda M, Nishizawa M, Segawa K, Tanaka M, Kishimoto K, Matsuki Y, Murakami M, Ichisaka T, Murakami H, et al. 2005 Visfatin: a protein secreted by visceral fat that mimics the effects of insulin. Science $\mathbf{3 0 7}$ 426-430. (https://doi.org/10.1126/ science.1097243)

Garces MF, Ruiz-Linares CE, Vallejo SA, Peralta JJ, Sanchez E, OrtizRovira A, Curtidor Y, Parra MO, Leal LG, Alzate JP, et al. 2015 Maternal serum omentin-1 profile is similar in humans and in the rat animal model. Cytokine 75 136-141. (https://doi.org/10.1016/j. cyto.2015.06.014)

Gluckman PD, Hanson MA \& Spencer HG 2005 Predictive adaptive responses and human evolution. Trends in Ecology and Evolution 20 527-533. (https://doi.org/10.1016/j.tree.2005.08.001)

Gluckman PD, Beedle AS, Hanson MA \& Vickers MH 2007a Leptin reversal of the metabolic phenotype: evidence for the role of developmental plasticity in the development of the metabolic syndrome. Hormone Research in Paediatrics 67 115-120. (https://doi. org/10.1159/000097566)

Gluckman PD, Lillycrop KA, Vickers MH, Pleasants AB, Phillips ES, Beedle AS, Burdge GC \& Hanson MA 2007b Metabolic plasticity during mammalian development is directionally dependent on early nutritional status. PNAS 104 12796-12800. (https://doi.org/10.1073/ pnas.0705667104)

Godfrey KM \& Barker DJ 2000 Fetal nutrition and adult disease. American Journal of Clinical Nutrition 71 1344S-1352S. (https://doi.org/10.1093/ ajcn/71.5.1344s)

Godfrey KM, Reynolds RM, Prescott SL, Nyirenda M, Jaddoe VW, Eriksson JG \& Broekman BF 2017 Influence of maternal obesity on the long-term health of offspring. Lancet: Diabetes and Endocrinology 5 53-64. (https://doi.org/10.1016/S2213-8587(16)30107-3)

Grayson BE, Kievit P, Smith MS \& Grove KL 2010 Critical determinants of hypothalamic appetitive neuropeptide development and expression: species considerations. Frontiers in Neuroendocrinology 31 16-31. (https://doi.org/10.1016/j.yfrne.2009.10.001)

Grove KL, Grayson BE, Glavas MM, Xiao XQ \& Smith MS 2005 Development of metabolic systems. Physiology and Behavior $\mathbf{8 6}$ 646-660. (https://doi.org/10.1016/j.physbeh.2005.08.063)

Halah MP, Marangon PB, Antunes-Rodrigues J \& Elias LLK 2018 Neonatal nutritional programming impairs adiponectin effects on energy homeostasis in adult life of male rats. American Journal of Physiology: Endocrinology and Metabolism 315 E29-E37. (https://doi.org/10.1152/ ajpendo.00358.2017)

Hales CN \& Barker DJ 2001 The thrifty phenotype hypothesis. British Medical Bulletin 60 5-20. (https://doi.org/10.1093/bmb/60.1.5) https://joe.bioscientifica.com

https://doi.org/10.1530/JOE-18-0686 (c) 2019 Society for Endocrinology Published by Bioscientifica Ltd. Printed in Great Britain 
Hamann A \& Matthaei S 1996 Regulation of energy balance by leptin. Experimental and Clinical Endocrinology and Diabetes 104 293-300. (https://doi.org/10.1055/s-0029-1211457)

Hanssens S, Marx-Deseure A, Lecoutre S, Butruille L, Fournel A, Knauf C, Besengez C, Breton C, Storme L, Deruelle P, et al. 2016 Maternal obesity alters the apelinergic system at the feto-maternal interface. Placenta 39 41-44. (https://doi.org/10.1016/j.placenta.2016.01.006)

Hauguel-De Mouzon S, Lepercq J \& Catalano P 2006 The known and unknown of leptin in pregnancy. American Journal of Obstetrics and Gynecology 194 1537-1545. (https://doi.org/10.1016/j. ajog.2005.06.064)

Hoggard N, Haggarty P, Thomas L \& Lea RG 2001 Leptin expression in placental and fetal tissues: does leptin have a functional role? Biochemical Society Transactions 29 57-63. (https://doi.org/10.1042/ bst0290057)

Holness MJ \& Sugden MC 2006 Epigenetic regulation of metabolism in children born small for gestational age. Current Opinion in Clinical Nutrition and Metabolic Care 9 482-488. (https://doi.org/10.1097/01. mco.0000232912.69236.e0)

Horvath TL \& Bruning JC 2006 Developmental programming of the hypothalamus: a matter of fat. Nature Medicine 12 52-53; discussion 53. (https://doi.org/10.1038/nm0106-52)

Howie GJ, Sloboda DM, Kamal T \& Vickers MH 2009 Maternal nutritional history predicts obesity in adult offspring independent of postnatal diet. Journal of Physiology 587 905-915. (https://doi.org/10.1113/ jphysiol.2008.163477)

Howie GJ, Sloboda DM \& Vickers MH 2012 Maternal undernutrition during critical windows of development results in differential and sex-specific effects on postnatal adiposity and related metabolic profiles in adult rat offspring. British Journal of Nutrition 108 298-307. (https://doi.org/10.1017/S000711451100554X)

Howie GJ, Sloboda DM, Reynolds CM \& Vickers MH 2013 Timing of maternal exposure to a high fat diet and development of obesity and hyperinsulinemia in male rat offspring: same metabolic phenotype, different developmental pathways? Journal of Nutrition and Metabolism 2013 517384. (https://doi.org/10.1155/2013/517384)

Jackson EK \& Li P 1997 Human leptin has natriuretic activity in the rat. American Journal of Physiology 272 F333-F338. (https://doi. org/10.1152/ajprenal.1997.272.3.F333)

Joss-Moore LA, Wang Y, Campbell MS, Moore B, Yu X, Callaway CW, Mcknight RA, Desai M, Moyer-Mileur LJ \& Lane RH 2010 Uteroplacental insufficiency increases visceral adiposity and visceral adipose PPARgamma2 expression in male rat offspring prior to the onset of obesity. Early Human Development 86 179-185. (https://doi. org/10.1016/j.earlhumdev.2010.02.006)

Kepczynska MA, Wargent ET, Cawthorne MA, Arch JR, O'dowd JF \& Stocker CJ 2013 Circulating levels of the cytokines IL10, IFNgamma and resistin in an obese mouse model of developmental programming. Journal of Developmental Origins of Health and Disease 4 491-498. (https://doi.org/10.1017/S2040174413000263)

Kieffer TJ \& Habener JF 2000 The adipoinsular axis: effects of leptin on pancreatic beta-cells. American Journal of Physiology: Endocrinology and Metabolism 278 E1-E14. (https://doi.org/10.1152/ ajpendo.2000.278.1.E1)

Kirk SL, Samuelsson AM, Argenton M, Dhonye H, Kalamatianos T, Poston L, Taylor PD \& Coen CW 2009 Maternal obesity induced by diet in rats permanently influences central processes regulating food intake in offspring. PLOS ONE 4 e5870. (https://doi.org/10.1371/ journal.pone.0005870)

Korner A, Garten A, Bluher M, Tauscher R, Kratzsch J \& Kiess W 2007 Molecular characteristics of serum visfatin and differential detection by immunoassays. Journal of Clinical Endocrinology and Metabolism 92 4783-4791. (https://doi.org/10.1210/jc.2007-1304)

Krechowec SO, Vickers M, Gertler A \& Breier BH 2006 Prenatal influences on leptin sensitivity and susceptibility to diet-induced obesity. Journal of Endocrinology 189 355-363. (https://doi.org/10.1677/joe.1.06679)
Lecoutre S, Deracinois B, Laborie C, Eberle D, Guinez C, Panchenko PE, Lesage J, Vieau D, Junien C, Gabory A, et al. 2016 Depot- and sexspecific effects of maternal obesity in offspring's adipose tissue. Journal of Endocrinology 230 39-53. (https://doi.org/10.1530/JOE-16-0037)

Lecoutre S, Marousez L, Drougard A, Knauf C, Guinez C, Eberle D, Laborie C, Vieau D, Lesage J \& Breton C $2017 a$ Maternal undernutrition programs the apelinergic system of adipose tissue in adult male rat offspring. Journal of Developmental Origins of Health and Disease 8 3-7. (https://doi.org/10.1017/S2040174416000702)

Lecoutre S, Oger F, Pourpe C, Butruille L, Marousez L, DickesCoopman A, Laborie C, Guinez C, Lesage J, Vieau D, et al. 2017b Maternal obesity programs increased leptin gene expression in rat male offspring via epigenetic modifications in a depot-specific manner. Molecular Metabolism 6 922-930. (https://doi.org/10.1016/j. molmet.2017.05.010)

Leonhardt M, Lesage J, Croix D, Dutriez-Casteloot I, Beauvillain JC \& Dupouy JP 2003 Effects of perinatal maternal food restriction on pituitary-gonadal axis and plasma leptin level in rat pup at birth and weaning and on timing of puberty. Biology of Reproduction $\mathbf{6 8}$ 390-400. (https://doi.org/10.1095/biolreprod.102.003269)

Lesage J, Del-Favero F, Leonhardt M, Louvart H, Maccari S, Vieau D \& Darnaudery M 2004 Prenatal stress induces intrauterine growth restriction and programmes glucose intolerance and feeding behaviour disturbances in the aged rat. Journal of Endocrinology 181 291-296. (https://doi.org/10.1677/joe.0.1810291)

Long NM, George LA, Uthlaut AB, Smith DT, Nijland MJ, Nathanielsz PW \& Ford SP 2010 Maternal obesity and increased nutrient intake before and during gestation in the ewe results in altered growth, adiposity, and glucose tolerance in adult offspring. Journal of Animal Science $\mathbf{8 8}$ 3546-3553. (https://doi.org/10.2527/jas.2010-3083)

Long NM, Ford SP \& Nathanielsz PW 2011 Maternal obesity eliminates the neonatal lamb plasma leptin peak. Journal of Physiology $\mathbf{5 8 9}$ 1455-1462. (https://doi.org/10.1113/jphysiol.2010.201681)

Long NM, Rule DC, Tuersunjiang N, Nathanielsz PW \& Ford SP 2015 Maternal obesity in sheep increases fatty acid synthesis, upregulates nutrient transporters, and increases adiposity in adult male offspring after a feeding challenge. PLOS ONE $\mathbf{1 0}$ e0122152. (https://doi. org/10.1371/journal.pone.0122152)

Lu SY, Qi SD, Zhao Y, Li YY, Yang FM, Yu WH, Jin M, Chen LX, Wang JB, He ZL, et al. 2015 Type 2 diabetes mellitus non-genetic rhesus monkey model induced by high fat and high sucrose diet. Experimental and Clinical Endocrinology and Diabetes 123 19-26. (https://doi.org/10.1055/s-0034-1385923)

Mark PJ, Sisala C, Connor K, Patel R, Lewis JL, Vickers MH, Waddell BJ \& Sloboda DM 2011 A maternal high-fat diet in rat pregnancy reduces growth of the fetus and the placental junctional zone, but not placental labyrinth zone growth. Journal of Developmental Origins of Health and Disease 2 63-70. (https://doi.org/10.1017/ S2040174410000681)

Mayeur S, Wattez JS, Lukaszewski MA, Lecoutre S, Butruille L, Drougard A, Eberle D, Bastide B, Laborie C, Storme L, et al. 2016 Apelin controls fetal and neonatal glucose homeostasis and is altered by maternal undernutrition. Diabetes 65 554-560. (https://doi.org/10.2337/db150228)

Mcmillen IC, Edwards LJ, Duffield J \& Muhlhausler BS 2006 Regulation of leptin synthesis and secretion before birth: implications for the early programming of adult obesity. Reproduction 131 415-427. (https://doi. org/10.1530/rep.1.00303)

Mela V, Diaz F, Lopez-Rodriguez AB, Vazquez MJ, Gertler A, Argente J, Tena-Sempere M, Viveros MP \& Chowen JA 2015 Blockage of the neonatal leptin surge affects the gene expression of growth factors, glial proteins, and neuropeptides involved in the control of metabolism and reproduction in peripubertal male and female rats. Endocrinology 156 2571-2581. (https://doi.org/10.1210/en.2014-1981)

Mela V, Jimenez S, Freire-Regatillo A, Barrios V, Marco EM, LopezRodriguez AB, Argente J, Viveros MP \& Chowen JA 2016 Blockage https://joe.bioscientifica.com https://doi.org/10.1530/JOE-18-0686 (c) 2019 Society for Endocrinology Published by Bioscientifica Ltd. Printed in Great Britain 
of neonatal leptin signaling induces changes in the hypothalamus associated with delayed pubertal onset and modifications in neuropeptide expression during adulthood in male rats. Peptides $\mathbf{8 6}$ 63-71. (https://doi.org/10.1016/j.peptides.2016.10.003)

Muhlhausler BS, Duffield JA \& Mcmillen IC 2007a Increased maternal nutrition increases leptin expression in perirenal and subcutaneous adipose tissue in the postnatal lamb. Endocrinology 148 6157-6163. (https://doi.org/10.1210/en.2007-0770)

Muhlhausler BS, Duffield JA \& Mcmillen IC 2007b Increased maternal nutrition stimulates peroxisome proliferator activated receptorgamma, adiponectin, and leptin messenger ribonucleic acid expression in adipose tissue before birth. Endocrinology 148 878-885. (https://doi.org/10.1210/en.2006-1115)

Myers MG, Cowley MA \& Munzberg H 2008 Mechanisms of leptin action and leptin resistance. Annual Review of Physiology 70 537-556. (https://doi.org/10.1146/annurev.physiol.70.113006.100707)

Paulsen ME, Rosario FJ, Wesolowski SR, Powell TL \& Jansson T 2018 Normalizing adiponectin levels in obese pregnant mice prevents adverse metabolic outcomes in offspring. FASEB Journal 33 2899-2909. (https://doi.org/10.1096/fj.201801015R)

Qasem RJ, Yablonski E, Li J, Tang HM, Pontiggia L, D'mello AP 2012 Elucidation of thrifty features in adult rats exposed to protein restriction during gestation and lactation. Physiology and Behavior 105 1182-1193. (https://doi.org/10.1016/j.physbeh.2011.12.010)

Qi SD, He ZL, Chen Y, Ma J, Yu WH, Li YY, Yang FM, Wang JB, Chen LX, Zhao Y, et al. 2015 Relevance and clinical significance of serum resistin level in obese T2DM rhesus monkey models. Experimental and Clinical Endocrinology and Diabetes 123 508-513. (https://doi. org/10.1055/s-0035-1554653)

Rajia S, Chen H \& Morris MJ 2010 Maternal overnutrition impacts offspring adiposity and brain appetite markers-modulation by postweaning diet. Journal of Neuroendocrinology 22 905-914. (https:// doi.org/10.1111/j.1365-2826.2010.02005.x)

Rattanatray L, Maclaughlin SM, Kleemann DO, Walker SK, Muhlhausler BS \& Mcmillen IC 2010 Impact of maternal periconceptional overnutrition on fat mass and expression of adipogenic and lipogenic genes in visceral and subcutaneous fat depots in the postnatal lamb. Endocrinology 151 5195-5205. (https:// doi.org/10.1210/en.2010-0501)

Rivera HM, Kievit P, Kirigiti MA, Bauman LA, Baquero K, Blundell P, Dean TA, Valleau JC, Takahashi DL, Frazee T, et al. 2015 Maternal high-fat diet and obesity impact palatable food intake and dopamine signaling in nonhuman primate offspring. Obesity 23 2157-2164. (https://doi.org/10.1002/oby.21306)

Rodriguez L, Panadero MI, Roglans N, Otero P, Alvarez-Millan JJ, Laguna JC \& Bocos C 2013 Fructose during pregnancy affects maternal and fetal leptin signaling. Journal of Nutritional Biochemistry 24 1709-1716. (https://doi.org/10.1016/j.jnutbio.2013.02.011)

Rodriguez L, Panadero MI, Roglans N, Otero P, Rodrigo S, AlvarezMillan JJ, Laguna JC \& Bocos C 2016 Fructose only in pregnancy provokes hyperinsulinemia, hypoadiponectinemia, and impaired insulin signaling in adult male, but not female, progeny. European Journal of Nutrition 55 665-674. (https://doi.org/10.1007/s00394-0150886-1)

Saad AF, Dickerson J, Kechichian TB, Yin H, Gamble P, Salazar A, Patrikeev I, Motamedi M, Saade GR \& Costantine MM 2016 High-fructose diet in pregnancy leads to fetal programming of hypertension, insulin resistance, and obesity in adult offspring. American Journal of Obstetrics and Gynecology 215 378.e1-378.e6. (https://doi.org/10.1016/j.ajog.2016.03.038)

Samuelsson AM, Matthews PA, Argenton M, Christie MR, Mcconnell JM, Jansen EH, Piersma AH, Ozanne SE, Twinn DF, Remacle C, et al. 2008 Diet-induced obesity in female mice leads to offspring hyperphagia, adiposity, hypertension, and insulin resistance: a novel murine model of developmental programming. Hypertension 51 383-392. (https:// doi.org/10.1161/HYPERTENSIONAHA.107.101477)
Sanchez-Garrido MA, Castellano JM, Ruiz-Pino F, Garcia-Galiano D, Manfredi-Lozano M, Leon S, Romero-Ruiz A, Dieguez C, Pinilla L \& Tena-Sempere M 2013 Metabolic programming of puberty: sexually dimorphic responses to early nutritional challenges. Endocrinology 154 3387-3400. (https://doi.org/10.1210/en.2012-2157)

Sato K, Takahashi T, Kobayashi Y, Hagino A, Roh SG \& Katoh K 2012 Apelin is involved in postprandial responses and stimulates secretion of arginine-vasopressin, adrenocorticotropic hormone, and growth hormone in the ruminant. Domestic Animal Endocrinology 42 165-172. (https://doi.org/10.1016/j.domaniend.2011.11.006)

Shasa DR, Odhiambo JF, Long NM, Tuersunjiang N, Nathanielsz PW \& Ford SP 2015 Multigenerational impact of maternal overnutrition/ obesity in the sheep on the neonatal leptin surge in granddaughters. International Journal of Obesity 39 695-701. (https://doi.org/10.1038/ ijo.2014.190)

Silvestre MF, Kieswich J, Yaqoob MM, Holness MJ, Sugden MC \& Caton PW 2014 A key role for interferon regulatory factors in mediating early-life metabolic defects in male offspring of maternal protein restricted rats. Hormone and Metabolic Research 46 252-258. (https://doi.org/10.1055/s-0034-1370933)

Sominsky L, Ziko I, Soch A, Smith JT \& Spencer SJ 2016 Neonatal overfeeding induces early decline of the ovarian reserve: implications for the role of leptin. Molecular and Cellular Endocrinology 431 24-35. (https://doi.org/10.1016/j.mce.2016.05.001)

Sominsky L, Ziko I, Nguyen TX, Quach J \& Spencer SJ 2017 Hypothalamic effects of neonatal diet: reversible and only partially leptin-dependent. Journal of Endocrinology 234 41-56. (https://doi. org/10.1530/JOE-16-0631)

Sonoli SS, Shivprasad S, Prasad CV, Patil AB, Desai PB \& Somannavar MS 2011 Visfatin - a review. European Review for Medical and Pharmacological Sciences 15 9-14.

Spencer SJ 2012 Early life programming of obesity: the impact of the perinatal environment on the development of obesity and metabolic dysfunction in the offspring. Current Diabetes Reviews 8 55-68. (https://doi.org/10.2174/157339912798829214)

Spicer LJ \& Francisco CC 1997 The adipose obese gene product, leptin: evidence of a direct inhibitory role in ovarian function. Endocrinology 138 3374-3379. (https://doi.org/10.1210/endo.138.8.5311)

Stastny J, Bienertova-Vasku J \& Vasku A 2012 Visfatin and its role in obesity development. Diabetes and Metabolic Syndrome 6 120-124 (https://doi.org/10.1016/j.dsx.2012.08.011)

Stocker C, O'dowd J, Morton NM, Wargent E, Sennitt MV, Hislop D, Glund S, Seckl JR, Arch JR \& Cawthorne MA 2004 Modulation of susceptibility to weight gain and insulin resistance in low birthweight rats by treatment of their mothers with leptin during pregnancy and lactation. International Journal of Obesity and Related Metabolic Disorders 28 129-136. (https://doi.org/10.1038/sj.ijo.0802476)

Stocker CJ, Wargent E, O'dowd J, Cornick C, Speakman JR, Arch JR \& Cawthorne MA 2007 Prevention of diet-induced obesity and impaired glucose tolerance in rats following administration of leptin to their mothers. American Journal of Physiology: Regulatory, Integrative and Comparative Physiology 292 R1810-R1818. (https://doi.org/10.1152/ ajpregu.00676.2006)

Sullivan EL, Smith MS \& Grove KL 2011 Perinatal exposure to high-fat diet programs energy balance, metabolism and behavior in adulthood. Neuroendocrinology 93 1-8. (https://doi. org/10.1159/000322038)

Sullivan EL, Riper KM, Lockard R \& Valleau JC 2015 Maternal high-fat diet programming of the neuroendocrine system and behavior. Hormones and Behavior 76 153-161. (https://doi.org/10.1016/j. yhbeh.2015.04.008)

Sullivan EL, Rivera HM, True CA, Franco JG, Baquero K, Dean TA, Valleau JC, Takahashi DL, Frazee T, Hanna G, et al. 2017 Maternal and postnatal high-fat diet consumption programs energy balance and hypothalamic melanocortin signaling in nonhuman primate offspring. American Journal of Physiology: Regulatory, Integrative and 
Comparative Physiology 313 R169-R179. (https://doi.org/10.1152/ ajpregu.00309.2016)

Tatemoto K, Hosoya M, Habata Y, Fujii R, Kakegawa T, Zou MX, Kawamata Y, Fukusumi S, Hinuma S, Kitada C, et al. 1998 Isolation and characterization of a novel endogenous peptide ligand for the human APJ receptor. Biochemical and Biophysical Research Communications 251 471-476. (https://doi.org/10.1006/ bbrc.1998.9489)

Taylor PD, Samuelsson AM \& Poston L 2014 Maternal obesity and the developmental programming of hypertension: a role for leptin. Acta Physiologica 210 508-523. (https://doi.org/10.1111/apha.12223)

Thompson NM, Norman AM, Donkin SS, Shankar RR, Vickers MH, Miles JL \& Breier BH 2007 Prenatal and postnatal pathways to obesity: different underlying mechanisms, different metabolic outcomes. Endocrinology 148 2345-2354. (https://doi.org/10.1210/en.2006-1641) Tuersunjiang N, Odhiambo JF, Shasa DR, Smith AM, Nathanielsz PW \& Ford SP 2017 Maternal obesity programs reduced leptin signaling in the pituitary and altered GH/IGF1 axis function leading to increased adiposity in adult sheep offspring. PLOS ONE 12 e0181795. (https:// doi.org/10.1371/journal.pone.0181795)

Udagawa J, Hatta T, Hashimoto R \& Otani H 2007 Roles of leptin in prenatal and perinatal brain development. Congenital Anomalies 47 77-83. (https://doi.org/10.1111/j.1741-4520.2007.00150.x)

Via M 2012 The malnutrition of obesity: micronutrient deficiencies that promote diabetes. ISRN Endocrinology 2012 103472. (https://doi. org/10.5402/2012/103472)

Vickers MH \& Sloboda DM 2012a Leptin as mediator of the effects of developmental programming. Best Practice and Research: Clinical Endocrinology and Metabolism 26 677-687. (https://doi.org/10.1016/j. beem.2012.03.005) programming

Vickers MH \& Sloboda DM 2012b Strategies for reversing the effects of metabolic disorders induced as a consequence of developmental programming. Frontiers in Physiology 3 242. (https://doi.org/10.3389/ fphys.2012.00242)

Vickers MH, Breier BH, Cutfield WS, Hofman PL \& Gluckman PD 2000 Fetal origins of hyperphagia, obesity, and hypertension and postnatal amplification by hypercaloric nutrition. American Journal of Physiology: Endocrinology and Metabolism 279 E83-E87. (https://doi.org/10.1152/ ajpendo.2000.279.1.E83)

Vickers MH, Reddy S, Ikenasio BA \& Breier BH 2001 Dysregulation of the adipoinsular axis - a mechanism for the pathogenesis of hyperleptinemia and adipogenic diabetes induced by fetal programming. Journal of Endocrinology 170 323-332. (https://doi.org/10.1677/joe.0.1700323)

Vickers MH, Gluckman PD, Coveny AH, Hofman PL, Cutfield WS, Gertler A, Breier BH \& Harris M 2005 Neonatal leptin treatment reverses developmental programming. Endocrinology 146 4211-4216. (https://doi.org/10.1210/en.2005-0581)

Vickers MH, Gluckman PD, Coveny AH, Hofman PL, Cutfield WS, Gertler A, Breier BH \& Harris M 2008 The effect of neonatal leptin treatment on postnatal weight gain in male rats is dependent on maternal nutritional status during pregnancy. Endocrinology 149 1906-1913. (https://doi.org/10.1210/en.2007-0981)

Walker CD, Naef L, D'asti E, Long H, Xu Z, Moreau A \& Azeddine B 2008 Perinatal maternal fat intake affects metabolism and hippocampal function in the offspring: a potential role for leptin. Annals of the New York Academy of Sciences 1144 189-202. (https://doi.org/10.1196/ annals.1418.023)

Zhang Y, Proenca R, Maffei M, Barone M, Leopold L \& Friedman JM 1994 Positional cloning of the mouse obese gene and its human homologue. Nature 372 425-432. (https://doi.org/10.1038/372425a0)

Received in final form 26 March 2019

Accepted 2 April 2019 (c) 2019 Society for Endocrinology Published by Bioscientifica Ltd. Printed in Great Britain 